\title{
Sacroiliac joint pain as an important element of psoriatic arthritis diagnosis
}

\author{
Agnieszka Krawczyk-Wasielewska'1, Elżbieta Skorupska², Włodzimierz Samborski² \\ ${ }^{1}$ Department of Physiotherapy, Poznan University of Medical Sciences, Poland \\ Head: Ewa Gajewska MD, PhD \\ ${ }^{2}$ Chair of Physiotherapy, Rheumatology and Rehabilitation, Poznan University of Medical Sciences, Poland \\ Head: Prof. Włodzimierz Samborski MD, PhD
}

Postep Derm Alergol 2013; XXX, 2: 108-112

DOI: 10.5114/pdia.2013.34161

\begin{abstract}
Psoriatic arthritis (PsA) is a chronic inflammatory disease characterized by the coexistence of arthritis with psoriasis of the skin and nails. The sacroiliac joints were observed in $34-78 \%$ of patients with psoriatic arthritis. Due to such a high prevalence of SIJ dysfunction, understanding pathophysiology of pain and the associated pain pattern becomes a very important aspect of PsA diagnosis. As far as the etiology of SI joint dysfunction is concerned, it has not been disambiguated yet. Among the main causative factors, injuries and strains of the structures surrounding the joint are noted. Joint pathology usually manifests itself by pain occurring within the area of the joint. The causes of pain may be divided into two categories: intra-articular and extra-articular. Pain caused by the SI joint may be nociceptive or neural in nature, whereas the pain pattern characteristic of the joint correlates with its innervation and is consistent with S2 dorsal rami.
\end{abstract}

Key words: sacroiliac joint, pain pattern, pathomechanism, psoriatic arthritis.

\section{Introduction}

Psoriatic arthritis (PSA) is a chronic inflammatory disease characterized by the coexistence of arthritis with psoriasis of the skin and nails. Psoriasis is observed in about $2 \%$ of the population, and in $10-50 \%$ of cases it is associated with arthritis [1-3]. About 20\% of patients with PsA have a severe and debilitating form of arthritis [4]. The pathogenesis of psoriatic arthritis indicates an autoimmune nature of the disease and specific involvement of T cells in the development of the inflammatory process $[5,6]$. It has been recently suggested that there is a relationship between the presence of enthesitis (inflammation of the attachment of ligaments, tendons, joint capsule and fascia to the bone), and the occurrence of PsA [7-9]. It is believed that inflammatory changes in the joints synovial membrane can be caused by inflammatory mediators derived from the adjacent inflamed tendons. Some researchers even considered enthesopathy as the primary source of disease [8]. Due to complex pathogenesis early diagnosis of patients with psoriatic arthritis is still difficult. The main diagnostic tools for patients evaluating are invariably physical examination, laboratory tests and imaging methods (X-rays and magnetic resonance imaging) [10, 11]. The most frequently used diagnostic criteria for PSA are Moll and Wright criteria:

1) an inflammatory arthritis (peripheral arthritis and/or sacroiliitis or spondylitis),

2) the presence of psoriasis,

3) the absence of serological tests for the rheumatoid factor [10].

Sacroiliitis (sacroiliac - SI) was found to be as high as $34-78 \%$ in patients with psoriatic arthritis and $14-23 \%$ of patients with psoriasis without articular involvement $[12,13]$. Articular changes are asymmetric in the majority of cases [3, 10, 11]. Some studies, however, confirmed the presence of bilateral changes even in $59 \%$ of patients with PSA [14]. Diagnosis of SI joint during the acute period is not a big diagnostic issue. However, the pathogenesis of strong pain emergence in this area in remission is not so clear. Knowledge of the pathophysiology of pain pattern formation associated with sacroiliac joint becomes a very important aspect of the diagnosis of PsA.

Address for correspondence: Agnieszka Krawczyk-Wasielewska, Department of Physiotherapy, Poznan University of Medical Sciences, 135/147 28 Czerwca 1956 r. St, 61-545 Poznan, Poland, phone: +48 692386 948, e-mail: krawczyk.agnieszka@wp.pl Received: 29.11.2012, accepted: 19.02.2013. 


\section{Definition and diagnosis}

In order to define pain caused by the SI joints, the following terms are used: SIJ dysfunction, SIJ syndrome, SIJ blockade, SIJ inflammation and SIJ pain. Some authors (especially those who deal with manual medicine and osteopathy) attempt to distinguish the above-cited terms [15]. It has been assumed that the term SIJ pain means the occurrence of pain in the area of the joint caused directly by the joint structure, whereas SIJ dysfunction means improper joint structure location or movement, which may or may not cause pain [15]. However, in the literature these terms are usually used interchangeably $[16,17]$.

Joint dysfunction is defined as a condition of mechanical changes characterized by the deviation from the expected norm (either by being too broad or too limited) as well as the occurrence of improper movements within the area of the joint [18]. Joint blockade is the term for the impairment of joint with limited or excessive mobility called motion segment dysfunction [19]. The examination and evaluation of the mobility within the joint is controversial because of the low sensitivity and reliability of diagnostic tests and the subjectivity of results.

Presently, the diagnostic criteria established in 1994 by the International Association Society for the Study of Pain (IASP) form the basis for the confirmation of this pathology [20]. The IASP diagnostic criteria include:

1) pain occurrence in the $S I$ joint area,

2) pain provocation through clinical tests characteristic of the SI joint,

3) intra-articular painkiller injection reducing or eliminating pain $[15,21]$.

\section{Etiology}

The etiology of SIJ dysfunction has not been disambiguated yet. Direct causes of pain occurrence within the SI joint following its characteristic pain pattern may be divided to:

1) intra-articular (degenerative diseases, microinjuries, inflammations),

2) extra-articular (changes in tendon tension, myofascial pain).

Pain caused by the SI joint may be nociceptive or neural in nature. Nociceptive pain is the effect of pain receptor irritation within the joint or the surrounding tissues, whereas neural pain is triggered by nerve ending irritation within the spinal nerves [22]. Nociceptive pain may stem from both intra-articular and extra-articular structures [23]. Neural pain is caused by extra-articular structures only [24].

\section{Extra-articular pathomechanism of pain}

The factors affecting the occurrence of pain of extraarticular origin include increasing of mutual compression load on joint structure and inflammation. Clinical studies have pointed to the dependence of lumbar spine stiffness and the SI joint. In patients after the surgical treatment of disc herniation with lumbar spine fusion, the hypermobility of SIJ and the increase in compression load on joint structure have been observed. Load within the joint depended on the spinal area, which had been surgically immobilized [25]. Another factor that may cause mechanical strain is anatomic shortening of the lower limb. The shortening may result in the increased friction within the joint, which may lead to its pathology and pain, particularly that subchondral structure of SIJ shows great sensitivity to compressive forces [4].

The importance of the inflammatory factor, in turn, has been proven by immunohistochemical studies confirming the existence of nociceptors in the superficial layers of sacrum cartilage. The receptors react to inflammatory factors (i.e. substance $P$ and CGRP protein), which shows that as the inflammation is initiated, SIJ structures may cause pain [23]. Suri proved that degenerative joint changes may increase nociceptor expression in cartilage [26]. Moreover, it has been noted that synovial fluid may occur beyond the joint area and, if it contains substance $P$, it may cause nerve irritation within the spinal area L4-S2 resulting in pain radiation into the lower limb $[27,28]$. Some authors claim that nociceptors are present also at the surface of both the sacroiliac and interosseous ligament $[19,30]$. If the inflammatory fluid finds itself beyond the area of the joint, pain receptors in the surrounding ligaments may be activated, which will become the direct cause of pain within the joint $[27,28]$.

\section{Extra-articular pathomechanism of pain}

Among the extra-articular factors the most frequently listed are changes in ligament tension, inflammation of the ligaments and articular capsule damage [25, 31, 32]. In patients with PsA, asymmetric enthesopathy is frequently observed in the early stages of the disease [33, 34]. Overload and microtrauma within the tendinous structures surrounding the joint may lead to the formation of inflammation within these structures.

Clinical studies show that the tendon inflammations may cause secondary inflammation within the synovial membrane [8]. Inflammation of the ligaments themselves will lead to increased tension and the subsequent emergence of pain.

According to Pool-Goudzwaard et al., improper tension in the area of the iliolumbar ligament may lead to the limitation of the mobility of the SI joint in the sagittal plane, especially during nutation [32]. The term nutation describes the anterior-inferior motion of the sacrum against the ilium that occurs during gait. Limited nutation increases the pressure on the posterior side of the sacrum and the compression of joints [35]. How the iliolumbar ligament influences the mobility of the SIJ depends great- 


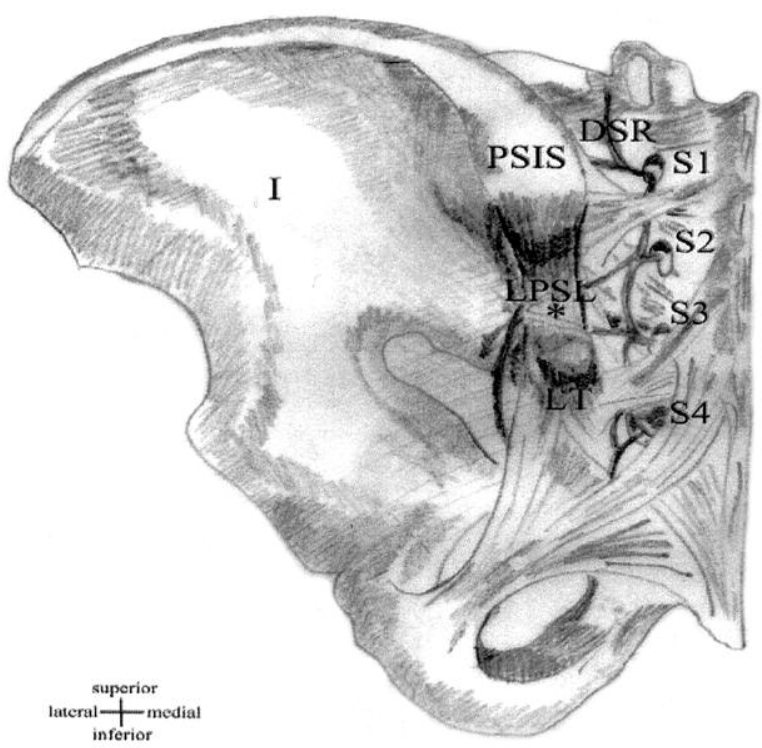

Figure 1. Anterior view on the sacroiliac joint [24] LPSL - long posterior sacroiliac ligament, PSIS - posterior superior iliac spine, $D S R$ - dorsal sacral rami
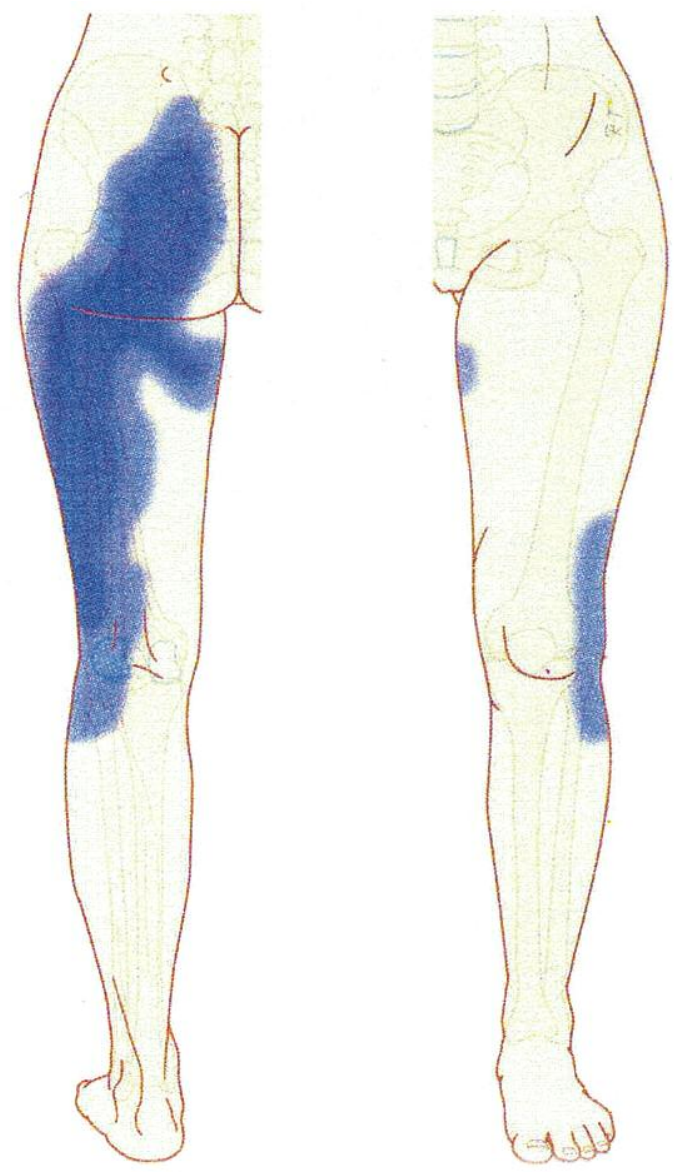

Figure 2. Typical location of pain in patients with SIJ dysfunction [43] ly on the position of the fifth lumbar vertebra. Side bending and twisting of the lumbar spine limit the mobility of the SIJ and increase the tension of the ligament at the side of the bending or at both sides during twisting. Hence, the tension is transferred to other ligaments and may result, in consequence, in pain caused by the ligaments themselves and their insertions [32]. The said pain may be referred pain, as many structures in this area have innervations convergent (the same level of the spinal cord) with the innervations of the iliolumbar ligament. For this reason, according to sensory neuron convergence, pain impulses may be transferred to these structures [36]. lliolumbar ligament irritation may cause pain in the area of the lumbosacral spine, as well as refer pain to the trochanteric region, groin and medial side of the thigh on the same side [37].

Anatomical and clinical studies have shown that long posterior sacroiliac ligament plays an important role in pseudoradicular pain generation in the area of buttocks. The correlation between the said ligament and lateral branches of the dorsal sacral rami of S2 (middle cluneal nerve), which may lead to neuropathy and result in pain in the given area, has been observed [38, 39]. The erector spinae aponeurosis, the gluteal aponeurosis and deep fascial layer together with the medial part of the sacroiliac ligament create a tunnel for the middle cluneal nerve (Figure 1). Changes in the tension in both gluteus maximus and gluteus medius muscle (caused by fall or injury) or erectors spinae are transferred to the ligament and cause the pressure of these structures on the nerve [35]. The pressure on the middle cluneal nerve leads to neuropathy and pain below the posterior superior iliac spine $[16,24,31]$.

\section{Symptoms}

Pain is the most typical symptom developed by SIJ pathology. However, stiffness and burning in the pelvis may also occur [40, 41]. Some researchers state that the change in the mobility within the SIJ area does not always lead to pain $[15,16]$. In $94 \%$ of cases, the symptoms characteristic of SIJ dysfunction concern the area of buttocks. In $72 \%$ of cases, the symptoms concern the lower part of the lumbar spine, while in $50 \%$ of patients they co-occur with the radiation to the lower limb (including $28 \%$ of patients with the radiation below the knee and $12 \%$ of patients with the radiation into the foot). SIJ impairments should be also associated with pain within the groin (14\%), the upper part of the lumbar spine (6\%) and the abdomen (2\%) [16, 21, 42]. Slimon et al. noticed statistically important dependence of age and the range of pain radiation. In patients under 40 years of age, pain radiated at least to the knee, whereas in older people pain was located mainly in the area of the buttocks [29]. The location of pain in patients with SIJ dysfunction is illustrated in Figure 2 below. Pain pattern presented in Figure 2 cor- 
relates with the innervations of the SI joint (especially S2 dorsal rami).

Additionally, in patients with SIJ dysfunction, areas of pain intensification have been observed. The area is as large as $3 \mathrm{~cm} \times 10 \mathrm{~cm}$ and is located below the posterior superior iliac spine. It is labeled Fortin's area [29, 42]. Pain occurs in this area in all patients diagnosed with SIJ pathology and in some patients with radicular pain. Moreover, in patients with the inflammation within the area of the sciatic nerve pain occurs also in the tuber area, which has not been confirmed in patients with SIJ dysfunction [44]. Pain occurrence in the Fortin's area proves the participation of the sacroiliac ligament and middle cluneal nerve in the pathology of the SI joint.

Pain aggravates when the joint is strained, especially when standing, walking, sitting for a long time (driving a car) or changing position in bed. The transition from the seated to standing position is particularly painful [40]. It should be also noted that pain occurring when standing up from the seated position is typical of the middle cluneal nerve neuropathy. When the nerve is damaged, this changing of positions becomes impossible. It has been confirmed by the image of the patient with SIJ dysfunction [16].

Knowledge of the pain pattern characteristic of the sacroiliac joint pathology appears to be useful in the diagnosis of psoriatic arthritis, especially in the early stages of the disease when it may be the only symptom of arthritis.

\section{References}

1. Veale D, Fitzgerald O. Psoriatic arthritis. Best Pract Res Clin Rheumatol 2002; 16: 523-35.

2. Veale DJ, Fitzgerald O. Psoriatic arthritis - pathogenesis and epidemiology. Clin Exp Rheumatol 2002; 20: 27-33.

3. Gladman DD, Antoni C, Mease P, et al. Psoriatic arthritis: epidemiology, clinical features, course and outcome. Ann Rheum Dis 2005; 64: 14-7.

4. Gladman DD. Psoriatic arthritis. Dermatol Ther 2009; 22: 40-55.

5. McGonagle D. Enthesitis: an autoinflammatory lesion linking nail and joint involvement in psoriatic disease. J Eur Acad Dermatol Venereol 2009; 23: 9-13.

6. Puszczewicz M, Iwaszkiewicz C. Role of anti-citrullinated protein antibodies in diagnosis and prognosis of rheumatoid arthritis. Arch Med Sci 2011; 7: 189-94.

7. Tan AL, McGonagle D. Psoriatic arthritis: correlation between imaging and pathology. Joint Bone Spine 2010; 77: 206-11.

8. McGonagle D, Conaghan PG, Emery P. Psoriatic arthritis: a unified concept twenty years on. Arthritis Rheum 1999; 42: 1080-6.

9. Rasmy H, Mikhael N, Ismail S. Interleukin-18 expression and the response to treatment in patients with psoriasis. Arch Med Sci 2011; 7: 713-9.

10. Helliwell PS, Taylor WJ. Classification and diagnostic criteria for psoriatic arthritis. Ann Rheum Dis 2005; 64: 3-8.

11. Ory PA, Gladman DD, Mease PJ. Psoriatic arthritis and imaging. Ann Rheum Dis 2005; 64: 55-7.
12. Baek HJ, Yoo CD, Shin KC, et al. Spondylitis is the most common pattern of psoriatic arthritis in Korea. Rheumatol Int 2000; 19: 89-94.

13. Battistone MJ, Manaster BJ, Reda DJ, et al. The prevalence of sacroiliitis in psoriatic arthritis: new perspectives from a large, multicenter cohort. A Department of Veterans Affairs Cooperative Study. Skeletal Radiol 1999; 28: 196-201.

14. Kaçar C, Sezer I, Kocabaş H, et al. Sacroiliac joint involvement in psoriasis. Rheumatol Int 2010; 30: 1263-6.

15. Laslett M. Evidence-based diagnosis and treatment of the painful sacroiliac joint. J Manual Manipulative Ther 2008; 16: $142-52$.

16. McGrath MC. Clinical considerations of sacroiliac join anatomy: a review of function, motion and pain. J Osteopath Med 2004; 7: 16-24.

17. Laslett M, Young SB, Aprill CN, et al. Diagnosing painful sacroiliac joints: a validity study of a McKenzie evaluation and sacroiliac provocation test. Aust J Physiother 2003; 49: 89-97.

18. Huijbregts P. Sacroiliac joint dysfunction: evidence-based diagnosis. Reh Med 2004; 8: 14-37.

19. Lewit K. Manual therapy in rehabilitation of the locomotor system. Publisher ZL "Nature", Kielce 2001.

20. Merskey H, Bogduk N. Classification of chronic pain: pain syndromes and definition of pain terms. $2^{\text {nd }}$ ed. IASP Press, Seattle 1996.

21. Vanelderen P, Szadek K, Cohen SP, et al. Sacroiliac joint pain. Pain Practice 2010; 10: 470-8.

22. Dobrogowski J, Wordliczek J. Pain medicine. PZWL, Warsaw 2005.

23. Szadek KM, Hoogland PVJM, Zuurmond WWA, et al. Possible nociceptive structures in the sacroiliac joint cartilage: an immunohistochemical study. Clin Anat 2010; 23: 192-8.

24. McGrath C, Nicholson H, Hurst P. The long posterior sacroiliac lingament: a histological study of morphological relations in the posterior sacroiliac region. Join Bone Spine 2009; 79: $57-62$

25. Ivanom AA, Kiapour A, Ebraheim NA, et al. Lumbag fusion leeds to increases in angular morion and stress cross saroiliac joint. Spine 2009; 34: 162-9.

26. Suri S, Gill SE, Massena de Camin S, et al. Neurovascular invasion at the osteochondral junction and in osteophytes in osteoarthritis. Ann Rheum Dis 2007; 66: 1423-8.

27. Fortin JD, Vilensky JA, Merkel GJ. Can the sacroiliac joint cause sciatica? Pain Physician 2003; 6: 269-71.

28. Vilensky JA, O'Connor BL, Fortin JD. Histologic analysis of neural elements in the human sacroiliac joint. Spine 2002; 27: $1202-7$.

29. Slimon CW, Jackson HB, Lipetz JS, et al. Sacroiliac joint pain referral zones. Arch Phys Med Rehabil 2000; 81: 334-8.

30. Szadek KM, Hoogland PV, Zuurmond WW, et al. Nociceptive nerve fibers in the sacroiliac joint in humans. Reg Anesth Pain Med 2008; 33: 36-43.

31. Cohen SP. Sacroiliac joint pain: a comprehensive review of anatomy, diagnosis and treatment. Anesth Analg 2005; 101: 1440-53.

32. Pool-Goudzwaard A, Van Dijke GH, Mulder P, et al. The iliolumbar lingament: its influence on stability of the sacroiliac joint. Clin Biomech 2003; 18: 99-105.

33. Girolomoni G, Gisondi P. Psoriasis and systemic inflammation: underdiagnosed enthesopathy. J Eur Acad Dermatol Venereol 2009; 23: 3-8.

34. Gisondi P, Tinazzi I, El-Dalati G, et al. Lower limb enthesopathy in patients with psoriasis without clinical signs of arth- 
ropathy: a hospital-based case-control study. Ann Rheum Dis 2008; 67: 26-30.

35. Vleeming A, Albert HB, Ostgaard HC, et al. European guidelines for the diagnosis and treatment of pelvic girdle pain. Eur Spine J 2008; 17: 794-819.

36. Freynhagen R, Rolke R, Baron R, et al. Pseudoradicular and radicular low back pain a diseases continuum rather then different entities? Answers from quantitative sensory testing. Pain 2008; 135: 65-74.

37. Dumas G, Leger A, Plamondon A. Fatigability of back extensor muscles and low back pain during pregnancy. Clin Biomech 2010; 25: 1-5.

38. Vleming A, De Vries HJ, Mens JM. Possible role of the long dorsal sacroiliac lingament in women with peripartum pelvic pain. Acta Obstet Gynecol Scand 2002; 8: 430-6.

39. McGrath MC, Zhang M. Lateral branches of dorsal sacral nerve plexus and the long posterior sacroiliac lingament. Surg Radiol Anat 2005; 27: 327-30.

40. Huijbregts P. Sacroiliac joint dysfunction: evidence-based diagnosis. Reh Med 2004; 8: 14-37.

41. Young S, Aprill C, Laslett M. Correlation of clinical examination characteristics with three sources of chronic low back pain. Spine J 2003; 3: 460-5.

42. Van der Wurff P, Buijs EJ, Groen GJ. Intensity mapping of pain referral areas in sacroiliac joint pain patients. J Manipulative Physiol Ther 2006; 29: 190-5.

43. Rogier Trompert Medical Art, http://www.medicalart.nl

44. Buijs E, Visser L, Groen G. Sciatica and the sacroiliac joint: a forgotten concept. Br J Anaesth 2007; 99: 713-6. 